\title{
The behavior of basic health insurance Organizations after the implementation of Relative Value of Health Services book in Iran: A qualitative study
}

\author{
Mani Yousefvand ${ }^{1}$, Alireza Olyaeemanesh*2, Mohammad Arab ${ }^{1}$, Ebrahim Jaafaripooyan ${ }^{1}$ \\ Received: 5 Sep 2017 \\ Published: 9 Nov 2018
}

\begin{abstract}
Background: Since approximately $45 \%$ of basic health insurance (BHI) resources are spent and distributed based on the Relative Value of Health Services (RVHS) book, therefore, any revision in this book will most probably affect the behavior of health insurance organizations. The present study was prospected to determine the effect of revising RVHS on behavior of BHI funds as the main providers of treatment resources.

Methods: This is a qualitative study in which data were analyzed using content analysis method. Semi-structured interviews were used to gather the required data. 27 interviewees were chosen using purposive sampling method. Finally, MAXQDA software was used to analyze and code the data.

Results: According to the results, revision of RVHS influenced the behavior of health insurance organizations. The most important changes in the behavior of health insurance funds involved the following: formation of a committee for cost management and handling the insurance documents, creating a uniform coding system for health services, redesigning the handling process of documents, increased share of insurance funds from health expenditures, with 300 new services added to basic package and revising the package according to the new version of the book. Furthermore, the rest of the changes included in the global payment method based on the new book, delay in paying claims, increased deductions based on the payment of expensive services on treatment protocols, holding periodic training courses, and teaching the new book as well as the procedures for handling the documents.

Conclusion: With regard to the revision of RVHS and considering the incremental approach in revision of relative values, the increased claims of health services delivery centers and delay in payment of these claims were the most important changes in the behavior of health insurance funds. Health policy makers can overcome such issues and provide proper financial conditions through reduction of conversion factor and mobilization of resources. Such policies will open the space for best management of the behaviors affected by revision of relative values.
\end{abstract}

Keywords: Relative value unit, Payment system, Physician fees, Behavior, Basic health insurance

Conflicts of Interest: None declared

Funding: Tehran University of Medical Sciences, Tehran, Iran

*This work has been published under CC BY-NC-SA 1.0 license.

Copyright $\odot$ Iran University of Medical Sciences

Cite this article as: Yousefvand M, Olyaeemanesh A, Arab A, Jafaripooyan E. The behavior of basic health insurance funds after the implementation of relative value of health services book in Iran: A qualitative study. Med J Islam Repub Iran. 2018 (9 Nov);32:110. https://doi.org/10.14196/mjiri.32.110

\section{Introduction}

According to the world health organization report in 2000, stewardship is the most important function of health systems (1). Since, "tariff" is -by itself- a governance tool for behavior status and known to be a leverage for policy making, thus, if these tariffs are defined based on technical and scientific grounds, they will have positive and proper effects on motivation and behavior of health sys-

Corresponding author:Dr Alireza Olyaeemanesh, arolyaee@gmail.com

1. Department of Health Management and Economics, School of Public Health, Tehran University of Medical Sciences, Tehran, Iran

2. Department of Payment and Financing of Health System, National Institute for Health Research, Tehran University of Medical Sciences, Tehran, Iran tem actors, expenditures, quantity and quality of services, accessibility, and people's satisfaction (2).

Relative value scale (RVS) model, broadly used by different countries, shows the variety and characteristics of payment to physicians $(3,4)$.

In Iran, the California's reference book is applied in order to use relative values for defining the tariff of health

$\uparrow$ What is "already known” in this topic:

There are no reports about the behavior of basic health insurance organizations after the implementation of RVU-Book in Iran.

\section{$\rightarrow$ What this article adds:}

This report has provided health policy makers with adequate financial and administrative information and may help them to implement the relative values appropriately. 
services (5). However, overlooking the framework and principles of the book while translating and compiling it into Persian has led to wrong establishment of this book within health system .In other words, over the time and by applying the annual coefficient to these tariffs, this issue has generated some class differences among medical groups $(6,7)$. Since most of the resource allocation is done based on health tariffs, therefore, improper establishment of tariffs has brought about some undesirable effects on continuity of health services (8).

Currently, Iran's health system lacks any clear policy for using tariff for health policy making. Thus, it faces some serious challenges such as exponential rise in health services costs $(4,9)$.

BHI in Iran is provided by four main insurance organizations; Social security organization covering $50 \%$ of the population, health insurance organization with $41 \%$, the armed forces medical services insurance organization with $7 \%$, and the Imam Khomeini Relief Committee with 2\% $(10,11)$.

In Iran, the book of relative values, which is also called the California Book, has been used as the basis for determining the physicians' fees since 1985 (12). In 2005, the Ministry of Health in collaboration with scientific-special associations published the relative values book which was not implemented due to its high financial burden and because of the resistance of basic insurance companies (6). Nevertheless, it was again published in 2009 , but later on it was stopped due to the objection of some special medical groups (13). In 2010, the Ministry of Health published the book for the third time, but again it was not implemented due to its financial burden for BHI companies and because of the changes in the basis and weight of relative value of services within book of 2009 (5). Having the "health sector evolution plan" implemented within health system, it provided the grounds for tariff revision and led to the publication of relative values book after almost 30 years in 2014. Approximately, 45\% of the treatment resources and basic insurance organizations is spent and distributed based on the relative values book, therefore, revision in this book will change the behavior of insurance organizations (14).

For this reason, health insurance organizations-as the main providers of financial resources- should be studied in order to determine their performance and policies influenced by revision in relative values. This information in turn will provide health policy makers with adequate financial and administrative tool and also help them to implement the relative values appropriately.

\section{Methods}

This is a qualitative study carried out by semi-structured interviews. Interviewees included top, middle, and operational managers of ministry of health, ministry of cooperatives, labor and social welfare, and BHI organizations who were quite familiar with the topic of study. Seven top managers, 11 middle managers, and nine operational managers were selected using purposive sampling method

Participants were chosen from various levels of health system. All participants were asked about the effect of revision in "health services relative value" on behavior of BHI organizations. Although, not also all participants were asked about the effect of this revision on their organization's behavior but nevertheless they expressed their views about its effect on other organizations' behavior. Having information about the topic and being interested in taking part in the study were the main criteria to choose the participants.

Data were collected using open questions and semistructured interviews. Information sheet and consent form were given to participants either through E-mails or in person before the interviews. Then, they were asked to let us know within a week whether they will agree on having interview or not. Interviews were continued until all related data gathered. Moreover, data collection methods, confidentiality of information, and the objective of the study were all cleared out for participants before the interviews.

Data analysis, collection, and transcribing of interviews were done all at the same time using content analysis method. In other words, all recorded interviews were listed first and then transcribed and, a list of themes and sub-themes were extracted. Next, the framework of themes were identified, classified and indexed. All these steps were carried out using MAXQDA-10 software.

In this study, internal validity was checked.by applied review methods used by participants in the research. An external observer used to increase the stability of research. For reliability, the long-term involvement of the researcher and his continuous observations in the research environment was considered.

\section{Results}

As pointed out earlier, the present study was aimed to identify the policy change of BHI organizations such as health insurance, social security, Imam Khomeini relief committee, and army health insurance due to the revision in relative value of health services. Table 1 is presented the themes and sub-themes of behavior change of organizations as well as the effect of revision in relative values on financial burden of these organizations.

\section{Organizational structure}

Organizational structure includes both formal and administrative structures (such as establishing a new office, adding some new duties to current one) and informal structures (such as creating a committee, website or virtual structures). In addition, redesigning informal structures were also studied as a current structure change. After implementing the "relative value of services" book and due to the established challenges as well as the changes in the financial burden and the payments, all BHI organizations decided to create a committee for preparing a "uniform procedure" under the management of secretariat of supreme council of health insurance.

\section{Changes in financial resources and premiums}

Financial resources and premiums of health insurance organizations include all inputs including budget rows, employers' share, insurer's share, government share or fixed Rial per capita which are monthly paid by insurers 
Table 1. The effect of revision in RVHS on behavior of BHI organizations

\begin{tabular}{|c|c|c|c|}
\hline & Theme & Sub-theme & The purpose of behavior change \\
\hline 1 & Organizational structure & $\begin{array}{l}\text {-Cost management committee } \\
\text {-Documents handling committee } \\
\text {-Uniform services coding system }\end{array}$ & $\begin{array}{l}\text {-Preparing procedures helps organizations in cost man- } \\
\text { agement and prevents from induced demand } \\
\text {-Reducing the patients out-of-pocket }\end{array}$ \\
\hline 2 & $\begin{array}{l}\text { Changes in financial resources } \\
\text { and premiums }\end{array}$ & $\begin{array}{l}\text {-Increased share of insurance organizations } \\
\text { from health expenditures } \\
\text {-Increased performance per capita propor- } \\
\text { tionate to increased salaries }\end{array}$ & $\begin{array}{l}\text {-Compensating some of the organization deduction } \\
\text {-Increased amount of resources for organizations }\end{array}$ \\
\hline 3 & $\begin{array}{l}\text { Population change and funds } \\
\text { pooling }\end{array}$ & Changes in size of covered population & Synchronization with universal coverage \\
\hline 4 & Insurance coverage package & $\begin{array}{l}\text {-Having } 300 \text { new services added to basic } \\
\text { package } \\
\text {-Preparing basic package based on new book } \\
\text {-New policies for reducing unnecessary } \\
\text { services } \\
\text {-Increased resistance against addition of new } \\
\text { services } \\
\text {-Reducing the co-payment for inpatients and } \\
\text { out-patients }\end{array}$ & $\begin{array}{l}\text {-Increased financial burden because of new services } \\
\text {-Management of current resources and creating a balance } \\
\text { between resources and costs } \\
\text {-Cost management } \\
\text {-Increased payable share of organization agreed upon } \\
\text { mutual understanding with ministry of health }\end{array}$ \\
\hline 5 & Payment system & $\begin{array}{l}\text {-Revising the global payment based on the } \\
\text { book } \\
\text {-Deletion of informal payments }\end{array}$ & $\begin{array}{l}\text {-Increased financial burden because of paying double } \mathrm{K} \\
\text { to the providers }\end{array}$ \\
\hline 6 & Payment of claims & $\begin{array}{l}\text {-Increased costs } \\
\text {-Delay in payment of claims }\end{array}$ & $\begin{array}{l}\text { - Accumulation of debt and claims due to delays in pay- } \\
\text { ments and an increase in the organization deficit }\end{array}$ \\
\hline 7 & Handling the documents & Increased deduction from 5 to $10 \%$ & -Reduced financial burden of new book \\
\hline 8 & Contracting & $\begin{array}{l}\text { Redesigning and preparing the contract } \\
\text { format }\end{array}$ & $\begin{array}{l}\text {-Management of interactions between services providers } \\
\text {-Cost management }\end{array}$ \\
\hline 9 & $\begin{array}{l}\text { Administrative processes (veri- } \\
\text { fication of documents, issuing } \\
\text { insurance cards...) }\end{array}$ & $\begin{array}{l}\text {-Redesigning the internal processes as well } \\
\text { as the process of handling the documents } \\
\text {-Relative payment of expensive services } \\
\text { based on medical protocols }\end{array}$ & Cost payment management and reduced financial burden \\
\hline 10 & $\begin{array}{l}\text { Process of coordination with } \\
\text { and training of provincial units }\end{array}$ & $\begin{array}{l}\text { Holding periodic training courses for new } \\
\text { book and its procedures }\end{array}$ & $\begin{array}{l}\text { Training the staff and experts helped to the better im- } \\
\text { plementation of book and preventing the cost increase }\end{array}$ \\
\hline
\end{tabular}

and employers. With regard to this issue, resources have not been properly pooled in all of the insurance organizations. The deficit of resources and delay in paying the insurance organizations claims after the implementation of relative value of the services certifies the aforementioned problem. Moreover, the most important behavior changes in terms of financial resources were the increased share of insurance organizations from health expenditures, and increased proportional premium per capita which induced by raising salaries, compensating some parts of the organization deficit, and increased resources of insurance organizations.

\section{Changes in population coverage and funds pooling}

Changes in the population due to the entrance or withdrawal of insured population were one of other issues pointed out by the interviewees. In addition, since insurance organizations own different funds, therefore, we decided to assess the pooling of these funds along with changes in the insured population. Due to the compulsory premiums and insurance coverage, there was not any change in the covered population for most of the basic insurance organizations such social security, government employee's fund of health insurance, and army health care insurance organization. Also, since premiums for rural health insurance and Imam Khomeini relief committee is free of charge, thus, there seemed to be no behavior change in the size of covered population. However, this was not true about funds with voluntary membership. Of course, we cannot disregard the effect of simultaneous implementation of universal health coverage plan and revision in relative values which increased its population from 1.5 million to 10 million. In other words, the revision in relative values and increased premiums of voluntary insurance funds caused most of these funds to be shifted towards universal health coverage funds in order to use free health care services.

\section{Health insurance coverage package}

Considering the insurance coverage cube (Fig. 1) (15) and with regard to its population coverage, two dimensions of "cost coverage" ,showed the deductible paid by the patients, and "service coverage" were studied. Since the relative values were revised almost after 30 years, therefore, it seems logical to have 300 new services added to the basic package. Of course, these new services were previously existed under the name of similar codes due to the patients need and with decision of providers. In other words, they were reported as informal and similar cases covered by the insurance organizations, but revision of

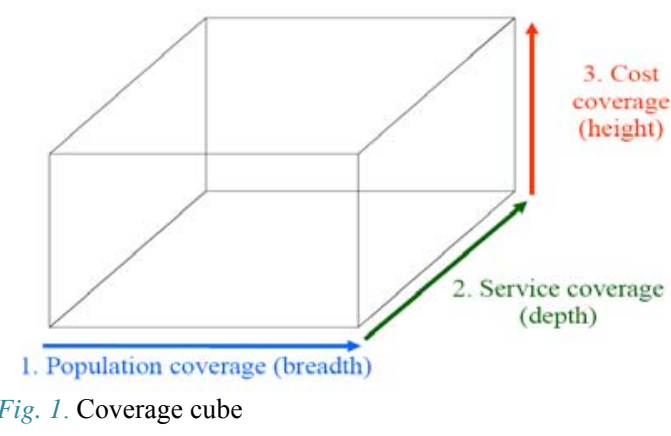

http://mjiri.iums.ac.ir

Med J Islam Repub Iran. 2018 (9 Nov); 32.110. 
relative values merely made them formal. According to this cube, in addition to population, there exists another dimension called cost coverage which is going to be discussed in two sections of basic and supplementary insurance (16).

Considering that the patients deductible is determined in advance for the basic insurance( $90 \%$ for inpatient services and $30 \%$ for outpatient services) (17), therefore, in line with new revision of relative values and with the decision of supreme council of insurance( session 55, on July 16, 2014), the former services along with 300 new services were insured. However, there seemed to be some challenges in supplementary insurance section due to the size of coverage and determining the ceiling of payable costs. Revision of relative values have created some disagreements among insurance companies with insured population. For instance, before the revision of relative values, the supplementary insurance used to cover 2.5 or at most 3 million of a $\mathrm{C}$-section cost within private hospitals. However, this amount was increased to 3.5 or 4 million after the revision $(18,19)$. Thus, supplementary insurance organizations needed to revise their ceiling of payable costs and they depended this on revision of premiums paid by the insured population.

\section{Payment system}

The main question here was the diversion from fee for service payment into other systems such as capitation, global budget, per case or per diem, or redesigning the current payment systems. Participants pointed out that revision of relative values may cause providers to report only one code for each medical record; in other words, we can see a per case system. Although, the prerequisites for such shift predicted within the book through code pooling, it was neglected and remained incomplete in the next steps. In result, revision in global services package was the only choice left due to the changes in the services values.

\section{Payment of claims}

The amount of financial documents of health care centers and hospitals sent to the insurance organizations at the end of each month is defined as hospitals claims from insurance companies. The present study mainly focused on the time and delay in paying these claims. Results indicated that paying these claims was the main behavior change of insurance organizations after the revision of relative values. These claims used to be paid with five to six months' delay before the health evolution plan. This time delay was decreased to two to three months at the first round of this plan. Increased governmental budgets, proper intersectional cooperation, non-delivering of insurance documents by hospitals, and unchanged hospital visits were the main reasons for this time delay reduction. However, revision in relative values increased the delay into seven to eight months. Operationalizing the relative value book, adapting the documents with the new book, increased hospital visits, and hence decreased financial resources of insurance organizations were among the main reasons for this problem.

\section{Handling the documents}

Handling the documents- for revision and filtering after sending them and claims by health organizations- are usually done by health insurance organizations to approve and assess the requested amount within the records. This process may change depending on the relations between providers and insurance companies. Handling the documents was one of the behaviors of health insurance organizations which directly affected by the revision in relative values. In addition, changes in the codes pooling and description as well as the variations in the guidelines and adjusting codes of new relative values were among the main reasons for such behavior change. Due to such changes, even the most skillful experts of hospital documents had problems with understanding the new terms and codes till some months after its implementation. The same problems occurred for the providers. Such issues for both providers and buyers increased the insurance deductions at early months. In result, providers started complaining about these problems which this in turn convinced the secretariat of supreme council of health insurance to announce the need for a uniform procedure for handling the documents.

\section{Contracting}

The relations between providers and buyers as well as the method of payment for the services is defined as contracting. Such contract between insurance companies and public health services providers has been exited as an unwritten treaty for many years based on the annual tariff enactment by delegation of ministers (such as enactment No. sor.rs/rroll, on May 19, 2016). According to this enactment, governmental organizations are mandated to have contract with basic insurance organizations. With revision in relative values and preparation of a uniform procedure for handling the documents, contract format was modified according to the needs and with regard to the types of health services delivery organizations.

\section{Adminstrative processes (verification of documents,} issuing insurance cards ...)

Verification of the documents and paying some other financial losses resulted from increased financial burden and costs of services delivered to the patients as well as cancelling the contract of some private health care facilities due to long delay in paying claims created some problems for the organizations. This is not added to the work volume of offices in charge of handling the documents but also made the responsible entities to think of revising and controlling the costs of patients. Therefore, they decided to redesign and modify the related processes. For instance, some insurance organizations stopped compensating the patients who had received services from noncontractual health centers.

\section{Training and coordination process of provincial} units

In this theme, the main question was about the cooperation method and training for provincial units as well as the methods for transferring the changes of new book. Some 
fundamental changes within the new book (such as codes pooling, variations in adjusting the codes, and codes reporting guidelines) made the cooperation and training process inevitably important. Considering the need for training the provincial units as well as the volume of these training courses, video conference was used within the health insurance organizations and ministry of health to meet the aforementioned goals. This was an innovation which was mainly affected by revision in relative values. Establishing websites, and designing the Android version of the new book were other activities aimed at training the provincial units. In other words, the revision of relative values of health services caused the responsible organizations to use innovative training methods.

\section{Discussion}

According to Baicker et al., higher value of health services can lead to increased premiums paid by the insured population (20). In line with this finding, the results of our study indicated that revision of RVHS and making tariffs more realistic could also increase per capita and premiums. Moreover, the behavior of handling the documents had also been affected by revision in relative values and had resulted in increased deduction. Furthermore, results of a study by Arentz et al. revealed that revision of and proposing a new model for tariffs can increase both the accuracy of handling the documents as well as the deduction of health services delivery centers. In addition, they pointed out that such changes provide necessary infrastructures for organizations and help them manage their information properly (21). Creating a new coding system for relative values offer essential grounds for establishing a better information bank and help organizations modify the current processes. According to Raghupathi et al, such macro information bank for health system improves the managerial processes (22). Moreover, results of a study by Swedloff et al indicated that there exists a direct correlation between price changes with changes in the rate of deduction. Such changes require organizations to design new forms for handling the documents which help organizations manage the deduction (23). The findings of our study were also in consistent with the preceding results.

Delay in paying the claims affects the motivation of providers and may even shift them towards receiving informal payments or delivering low quality services. Lewis in 2007 (24) and Cherecheş et al (25) in 2013 concluded that giving suitable motivation to providers is a fundamental solution for reducing the informal payments. Such behavior coming from providers has unpleasant impacts on patients and changes their view towards providers and insurance organizations. In result, it will make the insurance organizations inefficient (26).

Variations in training methods and advancement of technology, especially health related technologies, affect skills, efforts and other effective variables on determining the relative values (27). Therefore, annual revision of relative values is inevitable. Fortunately, such movement has been taken into account in article 38 (section $\mathrm{H}$ ) of fifth development plan act (28).

Since there was not any revision in relative values for the past 20 years especially after year 1994 and with approval of universal health insurance and hospital autonomy acts, thus there was a consensus among health system experts regarding the need for such revision. This consistency in relative values could be one of the reasons for the difference between Iran with other countries concerning the financial burden resulted from revision in relative values. For instance, in the United States between 2011 to 2015, they revised 833 services for which $23 \%$ had increased relative value, $26 \%$ with reduced relative value, and $51 \%$ with changes in description code (29). Doshmangir et al. have also pointed out the effect of revision in relative values on financial burden and increased costs of insurance organizations due to the augmenting growth of some services (8).

According to Christiansen et al., if insured population face with an increase in private insurance premiums, they seek to change their insurance and apply for an insurance plan with lower tariffs. On the other hand, insurance funds aim to have long-term contracts and try to prevent choosing from risk selection cases (30). Results of our study also indicated some changes in the size of insured population for universal health insurance fund. As pointed out by experts, a very important reason for such changes relied in simultaneous implementation of universal health coverage plan.

Increased share of insurance organizations from health expenditures was one of the other changes in the behavior of insurance companies. Such changes made insurance companies reconsider contracting with some private centers. These findings were also highlighted by Jabari et al (31).

\section{Conclusion}

Sever deficit of financial resources forced health insurance organizations to borrow money from banks. At the first look, it may seem that it speeded up claims payment, but in fact it increased the costs of health care centers by making them pay the money back to the banks with its profit.

Changes in the hidden layers of insurance organizations behavior was in different ways. The most important changes in this area included the following:

- Tendency to increase the deduction and making the claims payment process longer.

- Changes in the services package

- Issuing an organizational procedure for cost control

- Making the payment process more difficult

- Bargaining and negotiating for annual budget

If behavior change in organizational structure of insurance companies had occurred preventively and before the announcement of relative values, it may have had better outcomes. However, considering the limited time of ministry of health for recommending the new book to supreme council of health insurance and insurance organizations along with intensive work of related organizations did not give entities enough time to provide the framework and administrative grounds in advance.

Furthermore, one of the fundamental actions taken in regard to revision in relative values was the establishment 
of a committee responsible for revising and controlling the administrative instructions and guidelines related to the implementation of new book. Since such committees should be oriented towards reaching the predicted goals, therefore, the best way to meet such goal was to have special work groups within health insurance organizations that report back to supreme council of insurance. This would have helped the correct implementation of relative values as well as the proper management of financial control and physician's requests.

Financial burden resulted from revision in relative values is a permanent and long lasting change which will appear in expenditures of health insurance organizations in the future. However, some actions such as keeping the conversion factor fixed threatens the stability of financial resources for the current year. Moreover, since revision in relative values created an everlasting change in the basic costs of health insurance organizations, therefore, sustainable resources should be provided for such changes. Increased capitation and premiums proportionate to new services package price along with increased annual budget of insurance organizations would be among solutions in creating such sustainable resources.

What was neglected in revision of relative values turned out to be a great opportunity for health insurance organizations to review and modify their services package. Unfortunately, they could not take advantage of this opportunity. They could have prevented from unnecessary financial burden through creating appropriate, scientific filters for including the services in their package or even by determining a proper co-payment proportionate to the importance and levels of services. However, not also they did not use such chance but also added to their costs by unscientific coverage of new services.

Delay in paying the claims is one of the future threats for health care system. This may cause some harmful consequences such as rejecting the insured by contracting health care centers, cancelling the insurance contract, and shifting the health centers to receive informal payments.

\section{Limitations}

The limitation of this research was a small number of experts, with being familiar with the goals of the study.

\section{Acknowledgments}

This study was part of a health policy Ph.D. dissertation, with code of "9121557013", supported by Tehran University of Medical Sciences, Tehran, Iran.

The authors would like to thank Pejman Hamouzadeh, Farhad Habibi, Jalal Arabloo and Serajaddin Gray.

\section{Conflict of Interests}

The authors declare that they have no competing interests.

\section{References}

1. Stewart Jr J, Hedge D, Lester JP. Public policy: An evolutionary approach: Nelson Education; 2007.

2. Birkland TA. An introduction to the policy process: Theories, concepts and models of public policy making: Routledge; 2014.

3. Baadh A, Peterkin Y, Wegener M, Flug J, Katz D, Hoffmann JC. The relative value unit: history, current use, and controversies. Curr Probl Diagn Radiol. 2016;45(2):128-32.

4. Doshmangir L, Rashidian A. Methodology and challenges of making tariff, An overview on how to use Resource- Based Relative Value Scale (RBRVS) in determining physicians' payment rate. Homasal. 2011;41:18-23 (Persian).

5. Babashahy S, Baghbanian A, Manavi S, Sari AA, Manesh AO, Ronasiyan R. Towards reforming health provider payment methods: evidence from Iran. Health Scope. 2017;6(1).

6. Doshmangir L, Rashidian A, Akbari SA. Unresolved issues in medical tariffs: Challenges and respective solutions to improve tariff system in Iranian health sectors. J Hosp. 2012;10(4):21-30.

7. Zare H. The Handbook of Principles and Methods of Health Care Tariffs, ed. 1. Vol. 1. 2011, Tehran: Vajeh pardaz. (Persion).

8. Doshmangir L, Rashidian A, Moayeri F, Akbarisari A. Study the effect of proposed changes of different specialized medical tariff relative values on the payment weight of clinical expertise's and health system costs. Hakim Res J. 2011;14 (1):1-9.

9. Daroudi R, Akbari Sari A. Determining the reletaive value of common medical services in physiotherapy, speech therapy and occupational therapy according to resource based relative vaile scale moel in Iran [Dissertation]. Tehran University of Medical Sciences. 2012:71-6.

10. Mehrdad R. Health system in Iran. JMAJ. 2009;52(1):69-73.

11. Karimi I, Salarian A, Anbari Z. A comparative study on equity in access to health services in developed countries and designing a model for Iran. J Arak Uni Med Sci. 2010;12(4):92-104.

12. Ibrahimipour H, Maleki MR, Brown R, Gohari M, Karimi I, Dehnavieh R. A qualitative study of the difficulties in reaching sustainable universal health insurance coverage in Iran. Health Policy Plan. 2011;26(6):485-95.

13. Babashahy S, Akbari SA, Rashidian A, Olyaee MA. Payments of physicians employed in public and private hospitals after modification of surgical and invasive services tariffs. Hakim Res J. 2012;15(1).

14. Moradi-Lakeh M, Vosoogh-Moghaddam A. Health sector evolution plan in Iran; equity and sustainability concerns. IJHPM. 2015;4(10):637.

15. Chisholm D, Evans DB. Improving health system efficiency as a means of moving towards universal coverage. World Health Report. 2010.

16. Dehnavieh R, Rashidian A, Maleki M. Challenges of determining basic health insurance package in Iran. Payesh. 2011;10(2):273-283.

17. Zarei E, Pouragha B, Khodakarim S, Moosazadeh nasrabadi A. Out of Pocket Payment by Inpatients of Public Hospitals After Health Sector Evolution Plan A Cross-Sectional Study in Tehran City. Hospital. 2017;16(3):9-17.

18. Mohammadi E, Zareie G. Investigating the Effect of Health Care Improvement Plan on the Payment of the Insured in Iranian Health Insurance Organization (Case Study: Hospitalized Patients in Collegiate Hospitals of Ilam City in December 2013 and 2014). J Ilam Univ Med Sci. 2017;24(6):178-88.

19. Sarkhanlou F, Saeedi M, Janbabai G, Nikfar S, Morteza-Semnani K, Zaboli P. Comparative Study of Direct Patient and Drug Costs before and after the Implication of Healthcare Reform Program in Sari, Iran. J Mazandaran Univ Med Sci. 2016;26(142):228-32.

20. Baicker K, Mullainathan S, Schwartzstein J. Behavioral hazard in health insurance. Q J Econ. 2015;130(4):1623-67.

21. Arentz C, Rehm R. Behavior-based Tariffs in Health InsuranceCompatibility with the German System. Otto-Wolff-Discussion Paper 04/2016

22. Raghupathi W, Raghupathi V. Big data analytics in healthcare: promise and potential. Health Inf Sci Syst. 2014;2(1):3.

23. Swedloff R. Risk classification's big data (r) evolution. Conn Ins L J. 2014;21:339.

24. Lewis M. Informal payments and the financing of health care in developing and transition countries. Health Affairs. 2007;26(4):98497.

25. Cherecheş RM, Ungureanu MI, Sandu P, Rus IA. Defining informal payments in healthcare: a systematic review. Health Policy. 2013;110(2):105-14.

26. Laugesen MJ. The resource-based relative value scale and physician reimbursement policy. Chest. 2014;146(5):1413-9.

27. Kalantar M, Moaeiri F, Moazaami M. relative value units of health care services. 1 ed. Ministry of Health: Ministry of Health; 2009.

28. Ministry of Health and Medical Education (MoHME). Health Sector Evolution Portal. http://tahavol.behdasht.gov.ir/index.aspx?fkeyid=\& 
siteid=426\&pageid=52443. Accessed May 18, 2015

29. GAO. Medicare physician payment rates. Report to Congressional Committees: United States Government Accountability Office; 2015 May 2015. Contract No: GAO-15-434.

30. Christiansen MC, Eling M, Schmidt JP, Zirkelbach L. Who is changing health insurance coverage? Empirical evidence on policyholder dynamics. J Risk Insur. 2016;83(2):269-300.

31. Keyvanara M, Jabbari AR, Rahi F, Azizzadeh M. The challenges of the tariffs in medical services of health care system from the perspective of the managers of insurance agencies: A qualitative study. Hakim Res J. 2016;19(1):13- 24. 